\title{
Professionele richtlijn of juridisch kader?
}

\section{J.J.M. Besseling}

Op 30 maart jl. heeft het kabinet zijn standpunt bekendgemaakt inzake het langetermijnadvies van de Gezondheidsraad, 'Beoordelen, behandelen, begeleiden; medisch handelen bij ziekteverzuim en arbeidsongeschiktheid'. Kort gezegd komt het standpunt op het volgende neer. Voor de korte termijn geldt dat de Gezondheidsraad tien verzekeringsgeneeskundige protocollen opstelt. In december zijn de eerste twee, voor aspecifieke lage rugpijn en voor hartinfarct, gepubliceerd in de Staatscourant. Voor de langere termijn geldt dat in alle nieuwe multidisciplinaire medische richtlijnen die via de ZonMw-programmering lopen, de factor arbeid en de beoordeling van arbeidsmogelijkheden worden meegenomen. Het kabinet stelt tijdelijk extra middelen beschikbaar en er wordt onder andere voor de regiefunctie een begeleidingscommissie opgezet. Van deze multidisciplinaire richtlijnen kunnen verzekeringsartsen verzekeringskundige protocollen afleiden. Het kabinet geeft aan positief te staan tegenover de gedachte om uiteindelijk te komen tot $3 \mathrm{~B}$ richtlijnen.

Het is natuurlijk bijzonder positief dat kennis rond beoordelen, behandelen en begeleiden in relatie tot arbeid wordt geactualiseerd en dat het kabinet daar geld voor beschikbaar stelt. Toch is er ook aanleiding enkele kanttekeningen te plaatsen en verdient de ontwikkeling de warme, edoch kritische belangstelling van de beroepsgroepen. Met de introductie van de WIA werd door het kabinet het begrip duurzaamheid geïntroduceerd. In het WIA-voorstel is ook de poortwachtersrol van de bedrijfsarts verder uitgewerkt in de zogeheten plausibiliteitstoets. Daarbij wordt als een expliciet aandachtspunt genoemd of de behandelende sector heeft gehandeld volgens de algemeen gangbare richtlijnen. Kortom, de aanpassingen in het beoordelingsproces van de verzekeringsarts en de bedrijfsarts vormen voldoende reden om de beschikbare kennis en werkwijze te updaten. Maar naast de inhoudelijke overwegingen was er ook een politieke noodzaak om invulling te geven aan het nieuwe begrip duurzaamheid. Want door de toevoeging van dat nieuwe begrip dient de instroom van het aantal volledig arbeidsongeschikten verder af te nemen.

Het kabinet stelt in zijn brief van 30 maart dat de medische beroepsgroepen zelf verantwoordelijk zijn voor het integraal kwaliteitsbeleid en dat richtlijnontwikkeling een onderdeel is van dat kwaliteitsbeleid. (Overigens beschouw ik het als een opmerkelijk standpunt van de wetgever om de verantwoordelijkheid voor het integraal kwaliteitsbeleid waaronder de richtlijnontwikkeling bij de professionals te leggen. Mijns inziens zijn de uitvoeringsorganisaties primair verantwoordelijk voor de kwaliteit van de dienstverlening (door hun professionals) en moeten daarover verantwoording afleggen, maar dit terzijde.)

Een voorbeeld van de invulling van de eigen verantwoordelijkheid is de herziening van de Richtlijn lage rugpijn voor de bedrijfsartsen door de NVAB die deze zomer afkomt. Het resultaat van de werkzaamheden van de Gezondheidsraad het opstellen van verzekeringsgeneeskundige richtlijnen met een beperkte consultatieronde en publicatie door het kabinet in de Staatscourant waardoor de richtlijnen een formele, voorschrijvende status hebben gekregen - staat op gespannen voet met het uitgangspunt dat de medische beroepsgroepen zelf verantwoordelijk zijn voor hun integraal kwaliteitsbeleid.

Het opstellen van richtlijnen en protocollen is stap één. Het creëren van draagvlak en kennis laten nemen ervan door de beroepsgroepen zijn belangrijke voorwaarden om de beoogde kwaliteitsverbetering te realiseren. Het publiceren in de Staatscourant met daarbij een invoeringstermijn van een maand suggereert dat het protocol als juridisch kader is bedoeld in plaats van als professioneel kader. Het kabinet geeft in zijn brief ook niet aan hoe de tien verzekeringsgeneeskundige protocollen die de gezondheidsraad opstelt, worden geïmplementeerd, evenmin wat de nagestreefde beleidsdoelen en de beoogde kwaliteitsverbetering in meetbare termen en effecten zijn. Voor de bedrijfsartsen en verzekeringsartsen geldt dat ze in de komende tijd geacht worden kennis te nemen van een stroom van publicaties met actuele inzichten rond beoordelen, behandelen en begeleiden. Helaas is er geen meting geweest van de huidige kennis en kwaliteit van werken van bedrijfs- en verzekeringsartsen. Ik ben benieuwd of deze kennisimpuls van nieuwe protocollen en de nog komende 3B-richtlijnen effect zullen hebben op de kennis en de kwaliteit en effectiviteit van de dienstverlening van bedrijfs- en verzekeringsartsen, of, maar dat is wel een heel negatieve gedachte, is het slechts bedoeld als politiek glijmiddel voor de invoering van de WIA? 